Bangladesh J. Bot. 48(2): 373-378, 2019 (June)

\title{
GROWTH REGULATION AND OFF-SEASON FLOWERING THROUGH NIGHT BREAKS IN CHRYSANTHEMUM MORIFOLIUM RAMAT CV. ANMOL
}

\author{
TANya ThakUR* and HS Grewal \\ Department of Floriculture and Landscaping, Punjab Agricultural University, \\ Ludhiana, Punjab, India
}

Keywords: Chrysanthemum, Photoperiodic, Night Interruption, Anmol, Regulation

\begin{abstract}
The photoperiodic night interruption to schedule efficient flowering time in Chrysanthemum morifolium Ramat cv. Anmol according to demand of its flowers in the market was monitored. The influence of six night interruption treatments i.e. control, <5 second flash, 30, 60, 90 and 120 min were studied on the morphological development of Chrysanthemum morifolium Ramat cv. Anmol. The results revealed that the plant height, number of branches, leaves and root suckers per plant were positively affected with increased duration of night interruption. The flowering time was significantly delayed from mid December to end of February (two months) and number of flowers per plant increased as the duration of night interruption was increased from control to $120 \mathrm{~min}$. Therefore, the night interruption durations studies were helpful to schedule the sustainable flowering time in Chrysanthemum cultivar Anmol by around two months with better plant growth.
\end{abstract}

\section{Introduction}

Chrysanthemum morifolium Ramat ranked as the second most economical cut flower in the world, after rose (Kafi and Ghahsareh 2009) and is one of the photoperiodically controlled ornamental crops produced as both cut flower and pot plant (Van Der Ploeg and Heuvelink 2006). Photoperiod, day light exposure of plants, regulates morphological development in many floriculture crops like Poinsettia, Kalanchoe etc. The commercial growers provide long days through artificial lighting to maintain vegetative growth for cutting production in Chrysanthemum (Dole and Wilkins 2005) and to regulate flowering of photoperiod-sensitive species (Yamada et al 2008, Blanchard and Runkle 2009, Chen et al 2010). Chrysanthemum is a short-day plant with a critical day length of 13.5 hrs (Furuta 1954), so long-days (day-length $>12$ hrs) are maintained for 10 - 25 days so that the plants grow vegetatively (Carvalho 2003) and then plants are grown under short-day (day length $<12 \mathrm{hrs}$ ) leading to flower induction and development. The period between the start of the SD period and flowering under optimal conditions (reaction time) can vary between 6 - 11 weeks. In the open cultivation, the flowering of Chrysanthemum is confined only to limited period from October to December thus, the monitoring of photoperiod provides growers with an efficient crop schedule according to demand of flowers in the market. The phytochrome photoreceptors (R/FR) mediate light quality perception, stem elongation, and flowering in photoperiodic plants (Craig and Runkle 2012). The flowering of Chrysanthemum was inhibited by illuminating the plants with fluorescent or incandescent lamps by night interruption ('night break') with red light $(660 \mathrm{~nm})$ but subsequently irradiated far-red light $(730 \mathrm{~nm})$ induced the flowering, this photo-reversible flowering responses is regulated by the plant photoreceptor phytochrome B (Hong et al. 2013). Ishikura et al. (2009) reported that night break by emission of red light from an LED showed a similar effect with the use of an INC (incandescent) lamp on Chrysanthemum flowering inhibition. Incandescent lamps are used for night break treatment because of their good

*Author for correspondence: <tanyathakurflori@gmail.com>, <tanyaflori@pau.edu>. 
inhibitory effect (Hakuzan and Kooriyama 2013). This experiment was designed to investigate the effect of photoperiodic night interruption on morphological development and sustainable flowering of Chrysanthemum morifolium cv. Anmol.

\section{Materials and Methods}

The experiment was conducted at the Department of Floriculture and Landscaping, Punjab Agricultural University, Ludhiana, India during 2014-15. The terminal cuttings were taken from the mother stock plants pinched in end of May to encourage number of axillary shoots of spray type potted Chrysanthemum cultivar Anmol. The terminal cuttings $(5-7 \mathrm{~cm})$ were treated with IBA (Indole butyric acid) @ $400 \mathrm{mg} / \mathrm{l}$ and planted in burnt rice husk for rooting in June - July. The rooted cuttings were then transplanted during end July in the pots (6") containing mixture of soil and FYM $(2: 1)$ along with diammonium phosphate incorporated as a basal dose @ $1 \mathrm{~kg} / 100$ cubic feet. The plants were given night interruption (NI) treatments 45 days after planting (DAP) using incandescent bulbs (100 watt, $1.25 \mathrm{~m}$ above pot) for 2 months starting from $20^{\text {th }}$ September till $20^{\text {th }}$ November. Thereafter, the plants were kept under natural short-day open conditions. The experiment was conducted based on completely randomized design by replicating the treatment thrice. The night interruption was given starting from 22:00 to 24:00 as per the treatments- (i) T0 = control, (ii) $\mathrm{T} 1=<5$ second (flash of light), (iii) $\mathrm{T} 2=30 \mathrm{~min}$, (iv) $\mathrm{T} 3=60 \mathrm{~min}$, (v) $\mathrm{T} 4=90 \mathrm{~min}$ and (vi) T5 $=120 \mathrm{~min}$. The effect of different durations of night interruption on vegetative growth (at 15 days interval) and floral parameters were recorded, and statistical analysis was performed using SAS and treatment means were compared using DMRT (Duncan 1955).

\section{Results and Discussion}

The plant height $(\mathrm{cm})$, number of branches and leaves per plant after 15, 30 and 45 days of night interruption were significantly $(\mathrm{p}<0.05)$ influenced by all photoperiodic night interruption treatments (NI) as summarized in Table 1. The plant height after 15, 30 and 45 days of NI (34.55, 51.52 and $64.49 \mathrm{~cm}$, respectively) were significantly better in $120 \mathrm{~min}$. NI treatment than all other treatments. The plant height after 15 and 30 days of NI treatment increased with increased duration of NI but was significant with 90 and $120 \mathrm{~min}$. NI treatment $(28.57,43.74 \mathrm{~cm}$ and 34.55 , $51.52 \mathrm{~cm}$, respectively), whereas control, $<5 \mathrm{sec}$. flash, 30, 60 and $90 \mathrm{~min}$. NI treatment were at par among them.

The number of branches per plant after 15, 30 and 45 days of NI were significantly better in all treatments than the control $(1.75,2.04$ and 2.12, respectively) with maximum in $120 \mathrm{~min}$. NI treatments $(2.51,2.93$ and 3.20, respectively). The number of branches per plant at $120 \mathrm{~min}$. NI treatment was non-significant with 60 and $90 \mathrm{~min} \mathrm{NI}$ treatment (2.33 and 2.47, respectively) after 15 days of NI and with $<5 \mathrm{sec}$ flash, 30, 60 and $90 \mathrm{~min}$ NI treatment after 30 and 45 days of NI.

The number of leaves per plant after 30 and 45 days of night interruption (56.39 and 58.87) were significantly better in all treatments than the control and $<5 \mathrm{sec}$. flash NI treatment $(56.63$ and 61.41) which were at par among them, with maximum at $120 \mathrm{~min}$. NI treatment (69.58 and 77.44).

The effect of different photoperiodic treatment on number of root suckers per plant were significant $(\mathrm{p}<0.05)$ (Table 2). The number of root suckers per plant increased continually with increase in duration of NI treatments with maximum in 120 min. NI treatment (12.85). In 30, 60 and $90 \mathrm{~min}$. NI treatment the number of root suckers per plant (12.06, 12.09 and 12.53, respectively) were better than $<5 \mathrm{sec}$. flash NI treatment (11.59) but were at par among them. 


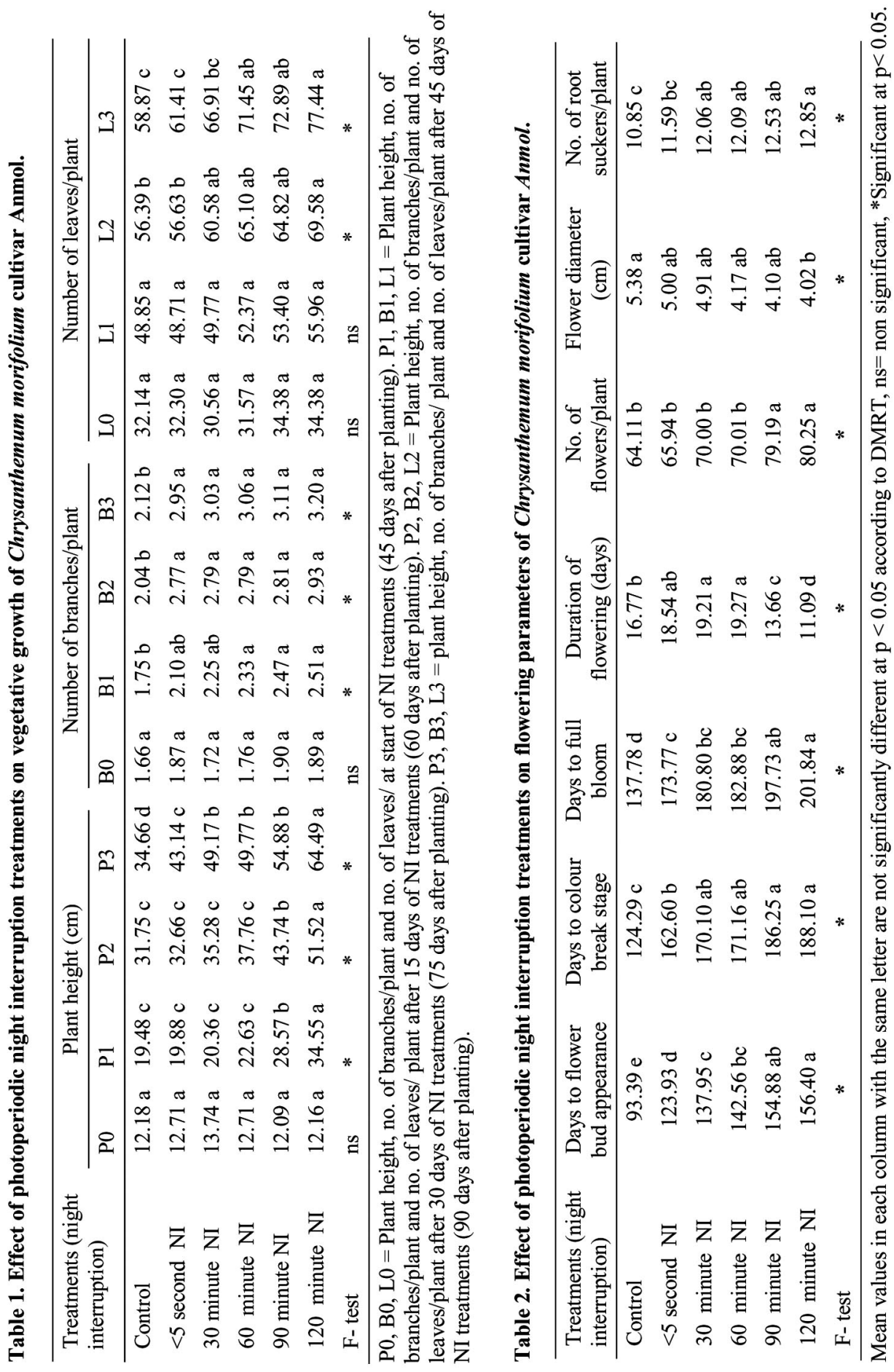


The vegetative parameters like plant height, number of branches, leaves and root suckers per plant increased continually with increase in the duration of NI treatments. In Chrysanthemum, for commercial production of cut stems, the plants maintained under long day conditions and proper night temperature promoted vegetative growth and attained the desired stem length before flower induction, as long stem fetch good market price (Datta and Gupta 2012). The increased plant height and growth rate result from enhanced photosynthetic activity under artificial long day conditions accompanied by accumulation of carbohydrate and nitrogen in the treated plants. Similar results were reported earlier by Kahar (2008), Thakur and Grewal (2018). The shoot length and number of leaves continually increased with the increase of the photoperiod from $8 \mathrm{hrs}$ to 24 hrs (Kurilcik et al. 2008).

The effect of different photoperiodic night interruption treatments on days taken to flower bud appearance, color break stage and full bloom were significant $(p<0.05)$ and the results are presented in Table 2. The days taken to flower bud appearance from date of planting increased continually with increased duration of photoperiodic night interruption treatment and were significantly better in all photoperiodic treatments than the control (93.39) when bud started to appear around the end of October. The maximum days to flower bud appearance was observed in $120 \mathrm{~min}$. NI treatment (156.40) where bud appeared in 1st week January and delayed the flower bud appearance by two months (around 63.01).

The days taken to color break stage from date of planting were significantly better in all photoperiodic treatments than the control (124.29) and color break stage started in end November. The days taken to color break stage was maximum in $120 \mathrm{~min}$. NI treatment (188.10) which was at par with 90- min. NI treatment (186.25) where bud appeared in end- January to 1st week of February and delayed the color break stage by two months. The 30 and 60 min. NI treatment delayed the color breaks stage which appeared in the month of end- December to mid- January.

The days taken to full bloom were significantly increased in all photoperiodic treatments than the control (137.78) where full blooming appeared in mid December, whereas maximum days to full bloom was recorded in $120 \mathrm{~min}$. NI treatment (201.84) followed by $90 \mathrm{~min}$. NI treatment (197.73) which delayed blooming by 64.06 and 59.95 days, respectively (around two months) and full bloom appeared in mid to end February.

There was delayed flowering under all photoperiodic treatments than under the control as the plants kept under the natural day length (control) completed their short-day requirement earlier for initiation and development of flower buds than different duration of photoperiodic treatments. This might also be due to low temperature conditions prevailing in December-January (12.3$11.3^{\circ} \mathrm{C}$ ) during the appearance of flower buds which further hindered the flower bud development. Higuchi et al. (2012) reported that short interruption (15 min) of the long-night phase effectively controlled flowering in Chrysanthemum plants that were grown under B light during their photoperiod. The long day conditions delayed days to flower by 42 days as compared to short days conditions (Kazaz et al. 2010, Kaur 2014). The flower bud appeared at the earliest in the plants without any exposure to the photoperiod. However, flower opening delayed with increase in day length exposure from six days to 15 days treatments (Kumar and Singh 2017). Similar results were reported by Thakur and Grewal (2016).

The quality parameters of flowers i.e. duration of flowering and flower diameter were negatively affected, whereas, number of flowers per plant significantly $(\mathrm{p}<0.05)$ increased with increase in duration of night interruption treatments (Table 2). There was significant reduction in duration of flowering at 90 and $120 \mathrm{~min}$. NI treatment (13.66 and 11.09 days) as compared to other treatments. The longest duration of flowering was observed in 60- min. NI (19.27 days) followed by $30 \mathrm{~min}$. NI treatments (19.21 days) which were at par among them. This reduction in 
duration of flowering under 90 and $120 \mathrm{~min}$. NI may be due to delayed flowering under these NI treatments which coincided with the increased temperature at the time of full flower opening in February $\left(16.3^{\circ} \mathrm{C}\right)$ than the other treatments in January $\left(11.3^{\circ} \mathrm{C}\right)$. The high temperature increased the respiration rate, depleted the plant of its carbon sources having adverse effect on longevity of the petals and caused hardening of stem which decreased the ability of the stem to absorb water. These results are in conformity with the findings of Kaur (2014).

There was reduction in flower diameter with increased duration of night interruption with minimum size recorded at $120 \mathrm{~min}$. NI $(4.02 \mathrm{~cm})$ and maximum at control $(5.38 \mathrm{~cm})$ which differs significantly from other treatments. The reduced flower diameter at $120-\mathrm{min}$. NI is mainly attributed to the decreased temperature during the flower bud appearance in January $\left(11.3^{\circ} \mathrm{C}\right)$ which hindered the expansion of flower buds (Kaur 2014). This might also be due to more diversion of photoassimilates towards the increased number of flowers per plant during longer duration of night interruption which furthers caused the lack of carbohydrates for development of size of flower bud. These results are in conformity with the findings of Thakur and Grewal (2016). The increased duration of night interruption increased the number of flowers per plant with maximum at 120- min. NI treatment (80.25) followed by 90- min. NI treatment (79.19) which were at par among them and differs significantly from other treatments. The increased number of flowers with increased night interruption duration might be attributed to the more vegetative growth coupled with stimulated branching and high carbohydrate synthesis with enhanced mobilization of assimilates by young sink tissues of growing lateral shoots (Verma et al. 2011). The artificial long days of $2 \mathrm{hrs}$ extended light resulted in the highest number of flowers per plant and flower yield (Velmurugan and Vadivel 2008).

In terms of overall performance, the vegetative growth was positively influenced, whereas the flowering was significantly delayed in all the photoperiodic night interruption treatments from mid- December (control) to end February (120 min. NI). Therefore, the study was effective to schedule the sustainable flowering time in Chrysanthemum cv. Anmol by around two months with better vegetative growth of the plant, which would help the farmers to get good price during off season.

\section{Acknowledgements}

The authors acknowledge the authority of the Department of Science and Technology (DST), under the Ministry of Science and Technology, Government of India for providing fellowship under the "INSPIRE Programme" to carry out this research work.

\section{References}

Blanchard MG and Runkle ES 2009. Use of a cyclic high-pressure sodium lamp to inhibit flowering of chrysanthemum and velvet sage. Sci. Hort. 122: 448-454.

Carvalho SMP 2003. Effects of growth conditions on external quality of cut Chrysanthemum: Analysis and Simulation. Ph.D. Thesis, Wageningen University, The Netherlands: 71.

Chen CL, Tsai YJ and Sung JM 2010. Photoperiod effect on flowering and seed setting of Hypericum perforatum. Exploring Agri. 46: 393-400.

Craig DS and Runkle ES 2012. Using LEDs to quantify the effect of the red to far-red ratio of night interruption lighting on flowering of photoperiodic crops. Acta Hort. 956:179-185.

Datta SK and Gupta VK 2012. Year-round cultivation of garden chrysanthemum (Chrysanthemum morifolium Ramat.) through photoperiodic response. Sci. \& Culture 78(1-2): 71-77.

Dole J and Wilkins H 2005. Floriculture Principles and Species. $2^{\text {nd }}$ ed. Prentice-Hall, Upper Saddle River, NJ, USA.

Duncan DB 1955. Multiple range and multiple F tests. Biometrics 11: 1-42. 
Furuta T 1954. Photoperiod and flowering of Chrysanthemum morifolium. Proceed. Amer. Soc. Hort. Sci. 63: $457-461$.

Hakuzan R and Kooriyama K 2013. Effect of night-break treatment at different times on inhibition of flower bud initiation in Chrysanthemum. Hort. Res. 12(4): 427-432 .

Higuchi Y, Sumitomo K, Oda A, Shimizu H and Hisamatsu T 2012. Day light quality affects the night-break response in the short-day plant chrysanthemum, suggesting differential phytochrome-mediated regulation of flowering. J. Plant Physio. 169:1789-1796.

Hong SC, Kwon SI, Kim MK, Chae MJ, Jung GB and So KH 2013. Flowering control by using red light of Chrysanthemum. Korean J. Env. Agri. 32(2): 123-127.

Ishikura S, Kajihara S, Harada H and Fukushima K 2009. Bulletin of Hiroshima Prefectural Technology Research Institute. Agri. Tech. Res. Center No. 84: 16.

Kafi M and Ghahsareh M 2009. Floriculture. 4th ed, pp. 108-118. Jahad Press, Tehran.

Kahar SAb 2008. Effects of photoperiod on growth and flowering of Chrysanthemum morifolium Ramat cv. Reagan Sunny. J. Trop. Agri. and Food Sci. 36(2): 1-8.

Kaur P 2014. Regulation of flower production and post-harvest keeping quality in chrysanthemum (Chrysanthemum morifolium Ramat). Ph.D. Dissertation, Punjab Agricultural University, LudhianaIndia.

Kazaz S, Askin MA, Kilic S and Ersoy N 2010. Effects of day length and daminozide on the flowering, some quality parameters and chlorophyll content of Chrysanthemum morifolium Ramat. Sci. Res. and Essays 5(21): 3281-3288.

Kumar S and Singh MC 2017. Effect of photoperiod on growth characteristics in Chrysanthemum morifolium Ramat. cv. Zembla using high pressure sodium light. Res. on Crops 18(1): 110-115.

Kurilcik A, Dapkuniene S, Kurilcik G, Žilinskaite S, Žukauskas A and Duchovskis P 2008. Effect of the photoperiod duration on the growth of Chrysanthemum plantlets in vitro. Scientific work of the Lithunian Institute of Horticulture and Lithunian Institute of Agriculture. Sodininkyste Ir Daržininkyste 27(2): 39-46.

Thakur T and Grewal HS 2016. Effect of duration of night interruption on growth and flowering of Chrysanthemum cv. Kikiobiory. J. App. Natural Sci. 8(2): 894-898.

Thakur T and Grewal HS 2018. Influence of Photoperiodic Night Interruption on Sustainable Potted Flower Production of Chrysanthemum cv. Snowball. Int. J. Current Microbio. App. Sci. 7(2): 1282-1287.

Van Der Ploeg A and Heuvelink E 2006. The influence of temperature on growth and development of chrysanthemum cultivars: a review. J. Hort. Sci. Biotech. 81(2): 174-182.

Velmurugan S and Vadivel E 2008. Effect of photoperiod and paclobutrazol on year-round flower production in Chrysanthemum. South Ind. Hort. 51(1/6): 51-59.

Verma SK, Angadi SG, Patil VS, Mokashi AN, Mathad JC and Mummigatti UV 2011. Growth, yield and quality of chrysanthemum (Chrysanthemum morifolium Ramat.) cv. Raja as influenced by integrated nutrient management. Karnataka J. Agri. Sci. 24(5): 681-83.

Yamada A, Tanigawa T, Suyama T, Matsuno T and Kunitake T 2008. Night break treatment using different light source promotes or delay growth and flowering of Eustoma grandiflorum (Raf.). Shinn. J. Japan Soc. Hort. Sci.77: 69-70.

(Manuscript received on 12 September, 2018; revised on 26 December, 2018) 